\title{
Altitudinal variation in ant-aphid mutualism in nitrogen transfer of oak (Quercus liaotungensis)
}

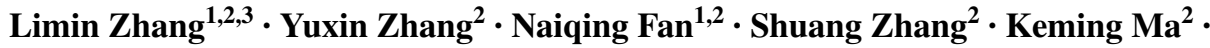 \\ Shukui Niu ${ }^{3}$
}

Received: 4 April 2016 / Accepted: 27 March 2017 / Published online: 13 April 2017

(C) Springer Science+Business Media Dordrecht 2017

\begin{abstract}
Ant-plant relationship is a model for the study of the ecology and evolution of interspecific interactions. In direct ant-plant mutualism (i.e., plants providing food or nesting places for ants, and ants protecting the plants in return) ants provide nutrients to plants. However, whether a similar mechanism exists in indirect ant-plant mutualism (i.e., an ant-aphid-plant system) remains unknown. In this work, we used the ${ }^{15} \mathrm{~N}$ stable isotope method to study altitudinal variations in the roles of ants in the nutrient transfer of oak (Quercus liaotungensis). Our work shows that ants deliver nitrogen in indirect ant-plant interactions, and that the effect of nutrient transfer differed significantly with altitude. Ants' trophic level at high altitudes was significantly lower than that at low altitudes, indicating that the degree of ant-aphid mutualism was greater at high altitudes, which may be beneficial in nitrogen transfer. Our work suggests that ant-aphid mutualism might be context dependent, such that it affects nutrient transfer in the food web, and that this context dependency is an important factor that influences altitudinal variation in nutrient transfer.
\end{abstract}

Handling Editor: Heikki Hokkanen.

Yuxin Zhang

yxzhang@rcees.ac.cn

Shukui Niu

shukuiniu@bjfu.edu.cn

1 School of Nature Conservation, Beijing Forestry University, Beijing 100083, People's Republic of China

2 State Key Laboratory of Urban and Regional Ecology, Research Center for Eco-Environmental Sciences, Chinese Academy of Sciences, Beijing 100085, People's Republic of China

3 College of Forestry, Beijing Forestry University, Beijing 100083, People's Republic of China
Keywords ${ }^{15} \mathrm{~N}$ stable isotope $\cdot$ Ant-aphid interaction . Context dependency $\cdot$ Nutrient transfer $\cdot$ Trophic level

\section{Introduction}

Interspecific interaction, a key component of biodiversity and ecosystem function, is a central issue in ecology (Palmer et al. 2008), and ant-aphid mutualism is a model system for the study of the ecology and evolution of this interaction (Heil and McKey 2003). Although ants are small, because they are predators with a wide distribution and include a large variety of species, they play very important roles in terrestrial ecosystems (Holldobler and Wilson 1990). Aphids excrete honeydew, an important food resource for ants (Buckley 1987; Rico Gray 1993). Honeydew has a high concentration of carbon, and extremely low concentration of nitrogen, which leads to an increased demand for nitrogen to balance the carbon-nitrogen ratio. Therefore, ants serve as predators of aphids' natural enemies and predators of other herbivores on leaves as well (Stadler and Dixon 2005). Ant-attended aphids excrete honeydew that has a higher concentration of amino acids, sucrose, and trehalose than do those of unattended aphids (Yao and Akimoto 2001). In addition, aphids can change the quality of their honeydew, which affects their mutualism with ants (Johansson and Gibb 2012). Studies have reported the effects of ant-aphid mutualism on plants, in which the absence of ants reduced the quantity of plant seeds and increased herbivore and leaf loss (Rosumek et al. 2009; Sipura 2002; Trager et al. 2010; Wimp and Whitham 2001).

In direct ant-plant mutualism, in which plants provide food or nesting places for ants, and in return, ants protect the plants from herbivores and supply nutrients to their host 
plants. Ants accumulate organic matter in their nests (e.g., leaf pouches, domatium, spongy-looking galleries, and petiolar chambers) by storing food, discarding debris, and defecating, and these activities may provide nutrients to the host plants (Defossez et al. 2009; Solano and Dejean 2004; Treseder et al. 1995). Using stable isotope analysis, Fischer et al. (2002) found up to $25 \%$ nitrogen transfer from ants to plants within 6 days, and Treseder et al. (1995) calculated that $39 \%$ of carbon and $29 \%$ of nitrogen in host plant leaves are derived from ant debris in the leaf cavities. Wagner and Nicklen (2010) tested the ant-derived nutrients assimilated by Acacia constricta, and found that 24 days after feeding ${ }^{15} \mathrm{~N}$-labeled food to Dorymyrmex sp. (Smithi complex) workers nesting near $A$. constricta, the ${ }^{15} \mathrm{~N}$-labeled plant leaves contained significantly higher levels of ${ }^{15} \mathrm{~N}$ than did those of $A$. constricta without an associated nest. It remains unknown whether a similar mechanism exists in indirect ant-plant mutualism (e.g., an ant-aphid-plant system). Soil-dwelling ants also deposit debris or defecate in and near their nests, and as a result, the soil near the nests becomes enriched with organic matter (Wagner and Nicklen 2010). Further, studies have reported higher nutrient cycling rates in soil associated with ant nests compared to those without (Jurgensen et al. 2008). Lasius fuliginosus usually nest in large plant roots or trunks where they may provide nutrients to host plants (Kalnihs and Dreimanis 2007). Therefore, we wished to test whether a nutrient transfer mechanism also exists in indirect L. fuliginosus $-Q$. liaotungensis mutualism.

Because stable isotopes are not hazardous, they are a simple, practical, and highly accurate method to use in these studies (Yi and Zhang 2005). Because $\delta^{15} \mathrm{~N}$ provides constant enrichment (approximately 3.4\%o) as the trophic level increases, ${ }^{15} \mathrm{~N}$ stable isotopes are powerful tools with which to evaluate the structure and dynamics of ecological communities (Post 2002). Analyzing ants' trophic level can reflect relationships among the organisms in the food web indirectly. For example, the trophic level of Solenopsis invicta is higher in their native country of Argentina, which implies that $S$. invicta forage there primarily as carnivores. However, when S. invicta invaded the United States, they established mutualism with honeydew-producing insects and occupied a lower trophic level (Gibb and Cunningham 2011). Because honeydew is a plant-based food source, the more the ants depend on honeydew, the lower their trophic level (Davidson et al. 2003). This change in the ants' trophic level also may affect nutrient transfer in the food web (Wilder et al. 2011).

In our previous research, we found that the altitudinal distribution of ant and aphid abundance differed significantly in the Dongling Mountain (the study area in this research), where the abundance of L. fuliginosus and the aphid, Lachnus tropicalis, at low altitudes was significantly higher than that at high altitudes (Zhang et al. 2015). These results provided the conditions necessary to study the context dependency of ant-aphid mutualism. Therefore, to understand this dependency, we used the ${ }^{15} \mathrm{~N}$ stable isotope method in this work to explore the ecological processes in the ant-aphid-plant system with respect to the ants' trophic level and nutrient transfer to determine whether the effect of nutrient transfer and the ants' trophic level varied with altitude.

\section{Materials and methods}

\section{Study area}

The study took place at the Beijing Forest Ecosystem Research Station located on Dongling Mountain $\left(30^{\circ} 057^{\prime} 29 \mathrm{~N}, 115^{\circ} 025^{\prime} 33 \mathrm{E}\right)$, which is part of the Chinese Ecological Research Network (CERN). This area has a warm, temperate, continental monsoon climate with a mean annual precipitation of 500-650 mm, and an average annual temperature of $5-10^{\circ} \mathrm{C}$ (Zhang et al. 2012). The annual frost-free period is approximately 195 days, with approximately $2600 \mathrm{~h}$ of sunshine. The altitude in most of the area is greater than $1000 \mathrm{~m}$ above sea level, with the highest peak at $2303 \mathrm{~m}$. The study was conducted in an 80-year-old oak ( $Q$. liaotungensis)-dominated secondary forest. $Q$. liaotungensis grows primarily from 1020 to $1770 \mathrm{~m}$ on sunny, semi-sunny, and semi-shady slopes, and usually is mixed with Betula platyphylla and Populus davidiana (Zhang et al. 2006).

\section{Experimental design}

The study was conducted at two sites: one at low altitude (1270-1360 m) and one at high altitude (1460-1560 m). At each site, three ant nests were designated as the control group and three were assigned to the treatment group. A ${ }^{15} \mathrm{~N}$-feeding experiment was performed in July and September 2014. Ants in the treatment group were fed ${ }^{15} \mathrm{~N}$-labeled glycine $\left(98\right.$ at. $\left.\%{ }^{15} \mathrm{~N}\right)$ aqueous honey solution $(30 \% \mathrm{w} / \mathrm{v}$, three times) for 15 days. We buried tinfoil bowls at ground level or slightly below, each of which contained $200 \mathrm{ml}$ of aqueous honey solution (totaling $5 \mathrm{~g}{ }^{15} \mathrm{~N}$-glycine for each nest). During labeling, the bowls were protected from rainfall with an inverted bowl and fixed with metal wires. Before and after the last were labeled at 5, 10, 20, 30, and 60 days, ants, soil, and leaves were sampled, respectively. Approximately 80-100 individual ants were collected from the trees. We cut three $Q$. liaotungensis twigs and picked six ripe leaves from each. The results showed that the ${ }^{15} \mathrm{~N}$ stable isotope enriched the soil primarily within $0-30 \mathrm{~cm}$ and accounted for approximately $70-85 \%$ within $0-100 \mathrm{~cm}$ 
(Yu et al. 2012). Therefore, five samples of soil surface grass and leaf litter were collected at each site within a radius of $1 \mathrm{~m}$ of the nest, after which approximately $10 \mathrm{~g}$ of soil taken within $15-20 \mathrm{~cm}$ was put into Ziploc bags. These samples were dried at $60^{\circ} \mathrm{C}$ for $48 \mathrm{~h}$ and kept dry until further analysis.

\section{Isotopic analysis}

Dried leaves and soil were ground into fine powder with a ball mill; the ants' abdomens were removed to avoid the influence of gut contents on the ${ }^{15} \mathrm{~N}$ values (Tillberg et al. 2006), and then were ground to powder with an agate mortar and pestle. Three leaf and five soil samples were mixed to ensure that the samples were homogeneous and representative. Samples weighing 1-20 mg were packed into tin capsules for isotopic analysis, and a total of 216 samples were analyzed. The ratio of heavy-to-light isotopes of $\mathrm{N}$ for all samples was measured using a continuous-flow isotope-ratio mass spectrometer (Finnigan Delta V Advantage, Finnigan MAT, San Jose, CA, USA) at the Stable Isotope Laboratory. The nitrogen stable isotope composition was expressed as $\delta(\%): \delta^{15} \mathrm{~N}(\% 0)=\left[\left(\mathrm{R}_{\text {sample }} /\right.\right.$ $\left.\left.R_{\text {standard }}\right)-1\right] \times 1000$, where $R$ is the ratio of ${ }^{15} \mathrm{~N} /{ }^{14} \mathrm{~N}$ of the sample and standard, and the isotopic standard for nitrogen is atmospheric $\mathrm{N}_{2}$ (Fischer et al. 2002; Gibb and Cunningham 2011).

\section{Analysis of ants' trophic level}

We used stable isotope analysis to estimate the ants' trophic level. In terrestrial ecosystems, roots, leaf litter, and herbivores are used commonly as a baseline (Ponsard and Arditi 2000). In our study, $\delta^{15} \mathrm{~N}_{\text {ant }}$ and $\delta^{15} \mathrm{~N}_{\text {leaf }}$ values from control nests were used to estimate ants' trophic level. The simplest model for estimating the trophic level of a secondary consumer is trophic level $=\lambda+\left(\delta^{15} \mathrm{~N}_{\text {secondary consumer }}-\delta^{15} \mathrm{~N}_{\text {base }}\right) /$ $\Delta \delta^{15} \mathrm{~N}$, where $\lambda$ is the trophic level of the organism used to estimate $\delta^{15} \mathrm{~N}_{\text {base }}$ (e.g., $\lambda=1$ for primary producers); $\delta^{15} \mathrm{~N}_{\text {secondary consumer }}$ is measured directly; and $\Delta \delta^{15} \mathrm{~N}$ is the fractional isotope values of adjacent trophic levels. All consumer levels were assumed to span 3.4\%o. In our study, the ants' trophic level was calculated as follows: trophic level $=\left(\delta^{15} \mathrm{~N}_{\text {ant }}-\delta^{15} \mathrm{~N}_{\text {leaf }}\right) / 3.4 \%$ o 1 (Post 2002) .

\section{Field survey}

We surveyed the abundance of terrestrial and arboreal ants, aphids, and the DBH of trees in all sites, and used pitfall traps to investigate the abundance of terrestrial ants, as this is a sampling method used extensively for surfaceforaging invertebrates (Cardoso et al. 2007; Wardle et al. 2011). Small $20 \mathrm{~m} \times 20 \mathrm{~m}$ plots were established at $2.5 \mathrm{~m}$ from the plot boundary, and a beaker (diameter $=7.9 \mathrm{~cm}$, depth $=9.7 \mathrm{~cm}$ ) was buried as a trap every $5 \mathrm{~m}$ at ground level or slightly below. Each beaker contained $50 \mathrm{ml}$ of $5 \%$ alcohol, and once every month from May to September 2009, we collected the ants after $48 \mathrm{~h}$ and recorded their total number. In order to reduce the boundary effect, we established large plots of $80 \mathrm{~m} \times 60 \mathrm{~m}$ in 2010 and 2011, and buried beakers only in the middle of the plots. The abundance of terrestrial ants and aphids, and the DBH of trees were measured in August 2013. For each nest, ten trees were selected that included three feeding routes in nine trees and the nest tree. Based on the nearest, farthest, and intermediate distances of each feeding route to the nest tree, we recorded a cross section of ants on every tree within $1 \mathrm{~min}$. To examine aphid abundance, we cut off three twigs randomly and recorded the number of aphid on 18 leaves. We measured the DBH of trees $1.3 \mathrm{~m}$ from the ground with a diameter tape. During the experiment, soil temperature was recorded automatically every hour by means of a button thermometer buried $10 \mathrm{~cm}$ below the surface.

\section{Statistical analysis}

We used $t$ tests to determine the differences between the control and treatment ants, soil, and leaves, and the data were $\ln$-transformed to reduce heterogeneity of variance; the ants' trophic level, tree $\mathrm{DBH}$, and soil temperature at different altitudes were analyzed similarly. SPSS 19.0 (SPSS, Chicago, IL, USA) was used for all analyses, and differences were considered significant at $p<0.05$. Related graphics were completed in Origin9.0.

\section{Results}

For the ${ }^{15} \mathrm{~N}$-labeled experiment, Table 1 shows the differences between treatments and controls in the $\delta^{15} \mathrm{~N}$ of ants, soil, and leaves at high- and low-altitude sites. As seen in the table, before labeling ( 0 day), there were no significant differences in the $\delta^{15} \mathrm{~N}$ values of ants and soil between the groups ( $p>0.05)$, while after labeling $(20,25,35,45$, and 75 days), there were significant differences $(p<0.05)$. The $\delta^{15} \mathrm{~N}$ of values ants and soil in the treatment groups were significantly higher than those in the controls, both at the high- and low-altitude sites (Fig. 1a, b). The $\delta^{15} \mathrm{~N}$ of leaves yielded similar results at low-altitude sites, but there was a significant difference in $\delta^{15} \mathrm{~N}$ in leaves between treatments and controls at high-altitude sites before labeling. To eliminate this significant difference, we analyzed the relative increment of $\delta^{15} \mathrm{~N}$ in leaves $\left(\delta^{15} \mathrm{~N}\right.$ of control and treatment leaves after labeling minus $\delta^{15} \mathrm{~N}$ of leaves before labeling, respectively). Table 2 shows that after labeling, 
Table 1 Differences of ants', soil's, leaves' $\delta^{15} \mathrm{~N}$ values between treatments and controls in high-altitude and low-altitude sites

\begin{tabular}{lllllrl}
\hline Variables & Time (days) & $d f$ & \multicolumn{1}{l}{$T_{1}$} & $P_{1}$ & \multicolumn{1}{l}{$T_{\mathrm{h}}$} & $P_{\mathrm{h}}$ \\
\hline Ants & 0 & 1,4 & 1.484 & 0.212 & -0.423 & 0.694 \\
& 20 & 1,4 & -16.629 & 0.000 & -14.125 & 0.000 \\
& 25 & 1,4 & -21.606 & 0.015 & -22.403 & 0.000 \\
& 35 & 1,4 & -12.806 & 0.000 & -7.734 & 0.002 \\
& 45 & 1,4 & -4.036 & 0.016 & -14.547 & 0.000 \\
Soil & 75 & 1,4 & -5.902 & 0.004 & -7.199 & 0.002 \\
& 0 & 1,4 & 0.616 & 0.571 & -2.090 & 0.105 \\
& 20 & 1,4 & -4.915 & 0.008 & -11.579 & 0.000 \\
& 25 & 1,4 & -4.665 & 0.010 & -5.490 & 0.005 \\
& 35 & 1,4 & -2.783 & 0.050 & -4.205 & 0.014 \\
& 45 & 1,4 & -2.770 & 0.050 & -5.745 & 0.005 \\
Leaves & 75 & 1,4 & -5.614 & 0.005 & -5.742 & 0.005 \\
& 0 & 1,10 & -1.335 & 0.211 & -3.328 & 0.008 \\
& 20 & 1,10 & -2.324 & 0.042 & -6.434 & 0.000 \\
& 25 & 1,10 & -3.083 & 0.012 & -7.535 & 0.000 \\
& 35 & 1,10 & -2.679 & 0.029 & -5.609 & 0.000 \\
& 45 & 1,10 & -2.909 & 0.016 & -5.614 & 0.000 \\
& 75 & 1,10 & -2.742 & 0.021 & -7.788 & 0.000 \\
\hline
\end{tabular}

$P_{1}$ : significance between treatments and controls in low-altitude sites, $P_{\mathrm{h}}$ : significance between treatments and controls in high-altitude sites
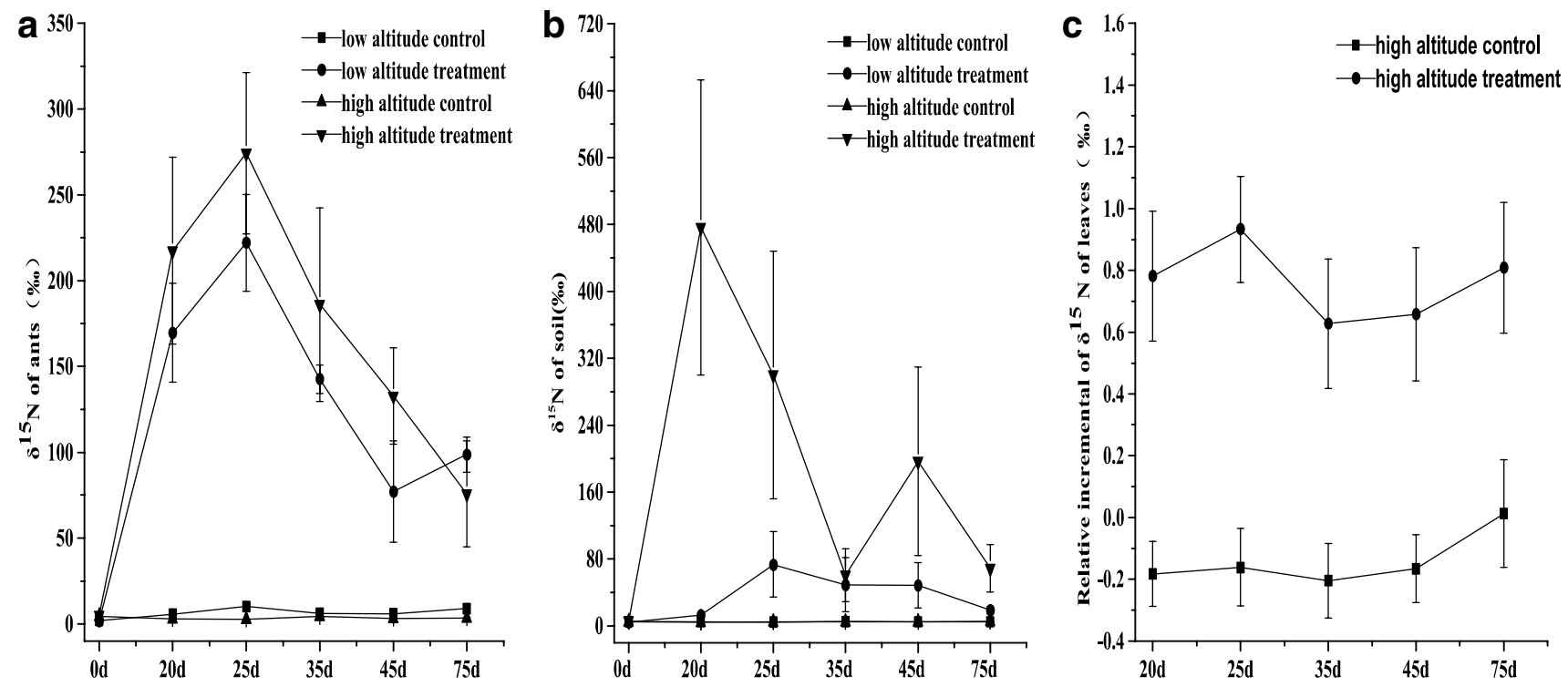

Fig. 1 Differences of variables along the altitude. a Difference of ants' $\delta^{15} \mathrm{~N}$ between treatments and controls in high-altitude and lowaltitude sites; $\mathbf{b}$ difference of soil's $\delta^{15} \mathrm{~N}$ between treatments and con- trols in high-altitude and low-altitude sites; c difference of relative incremental of leaves' $\delta^{15} \mathrm{~N}$ between treatments and controls in highaltitude site. Error bars represent SEs the difference in $\delta^{15} \mathrm{~N}$ of leaves between controls and treatments was significant at high-altitude sites $(p<0.05)$, in that the relative increment in $\delta^{15} \mathrm{~N}$ of leaves at treatment sites was significantly higher than that of controls (Fig. 1c).

To explore whether the effect of nitrogen transfer differed with altitude, we analyzed the relative increment of $\delta^{15} \mathrm{~N}$ in ants, soil, and leaves. Table 3 shows that there was no significant difference in the relative increments of $\delta^{15} \mathrm{~N}$ in ants and leaves between the treatment and control groups at high- and low-altitude sites $(p>0.05)$, but the difference in soil's $\delta^{15} \mathrm{~N}$ was significant $(p<0.05)$. As shown, the relative increment of $\delta^{15} \mathrm{~N}$ in soil in 
Table 2 Differences of the relative incremental leaves' $\delta^{15} \mathrm{~N}$ between treatments and controls in high-altitude sites

\begin{tabular}{llll}
\hline $\begin{array}{l}\text { Leaves } \\
\text { (days) }\end{array}$ & $d f$ & $T$ & $P$ \\
\hline 20 & 1,10 & -4.094 & 0.002 \\
25 & 1,10 & -5.152 & 0.000 \\
35 & 1,10 & -3.440 & 0.006 \\
45 & 1,10 & -3.411 & 0.007 \\
75 & 1,10 & -2.908 & 0.016 \\
\hline
\end{tabular}

Table 3 Differences of the relative increments of ants', soil's, leaves' $\delta^{15} \mathrm{~N}$ between treatments in high-altitude and low-altitude sites

\begin{tabular}{llll}
\hline Variable & $d f$ & $T$ & $P$ \\
\hline Soil & 1,28 & -4.158 & 0.000 \\
Ants & 1,28 & -0.581 & 0.566 \\
Leaves & 1,58 & -0.543 & 0.589 \\
\hline
\end{tabular}

high-altitude treatments was significantly higher than that at low altitudes.

We also analyzed the altitudinal variation in the trophic level of ants from control nests between high and low altitudes, and found that their trophic level at high altitude was significantly lower than that at low altitude $\left(t_{1,40}=2.55\right.$, $p<0.05)$. The DBH of trees at high altitude also was significantly larger than that at low altitude $\left(t_{1,118}=-2.09\right.$, $p<0.05)$. However, although it was slightly lower at high-altitude $(14.01 \pm 0.39)$ than that at low-altitude sites $(15.08 \pm 0.47)$, the difference in soil temperature was not significant $\left(t_{1,52}=1.77, p>0.05\right)$.

\section{Discussion}

We performed a ${ }^{15} \mathrm{~N}$-labeled experiment to examine the effects of nitrogen transfer in indirect ant-plant mutualism. Results showed that after labeling, the $\delta^{15} \mathrm{~N}$ of ants, soil, and leaves were significantly higher than those before labeling. This demonstrated that the debris and feces that ants deposit in belowground nests enrich the soil organic matter-the result that is consistent with previous findings (Wagner and Nicklen 2010). According to these results, nutrient transfer from ants to plants may occur both through soil and by ants' supplying nutrients directly. Because the belowground system is complex, its role in the transfer process of animals in the soil, microorganisms, and roots remains unclear. Therefore, future studies should focus on the process of nutrient transfer and quantify the value of the contributions from ants to plants.

At our treatment sites, the $\delta^{15} \mathrm{~N}$ of soil differed significantly at high and low altitudes, which suggests that the effect of nutrient transfer on ant-aphid mutualism varies with altitude. Studies have reported that soil temperature may influence the isotope fractionation of mineralization, nitrification, and denitrification in nitrogen cycling and affect the activity of soil microorganisms. For example, when the temperature increased, the activities of the soil nitrobacteria and ammonifiers were strengthened, such that light isotopes reacted faster, and thus enriched more heavy isotopes (Zhong 2013). Nevertheless, in this study, we found that soil temperature was slightly higher at low altitudes, and soil's $\delta^{15} \mathrm{~N}$ at high altitudes was significantly higher, which suggests that soil temperature may not affect the nitrogen transfer in ant-plant mutualism significantly. In addition, temperature and precipitation are important environmental factors that affect leaves' $\delta^{15} \mathrm{~N}$ (Martinelli et al. 1999; Zhou et al. 2012). Previous studies in the Dongling Mountain have reported a significant negative relationship between tree leaves' $\delta^{15} \mathrm{~N}$ and precipitation, but a significant positive relationship with annual temperature (Liu et al. 2009). Thus, nutrient transfer should be explored with respect to both biotic and abiotic factors.

Plant size is an important factor that affects the ant-plant relationship. L. fuliginosus prefer to nest in larger trees, which therefore may play an important role in mutualism (Zhang et al. 2012). Results have shown that trees' DBH is significantly greater at high altitude, but the $\delta^{15} \mathrm{~N}$ of leaves is not. This indicates that larger plants may not promote nitrogen transfer in indirect ant-plant interactions. This is consistent with the findings that tree size does not influence the ecological effects of indirect ant-plant interactions (Zhang et al. 2012).

The more the ants depend on plant-based foods (e.g., honeydew), the lower their trophic level. Our work showed that ants' trophic level at high altitudes was significantly lower than that at low altitudes. This indicates that ants at higher-altitude sites depend more on plant-based food (e.g., honeydew), which suggests that there may be a greater degree of ant-aphid mutualism at high altitudes. Recent studies have shown that higher ant abundance is related to lower trophic level as well (Davidson et al. 2003; Zhang et al. 2015). In contrast to previous studies, our results showed that a higher trophic level was associated with higher ant abundance at low altitudes. This could happen if there is a shortage of protein-based food (e.g., herbivores), in which case ants may eat their mutualist partner, the aphid, to maintain a balanced nitrogen-carbon diet (Petry et al. 2012). At the lower-altitude site, the higher abundance of ants demands more protein-based foods. When there is a shortage of other sources of protein-based foods (other herbivores than aphids), ants may eat aphids to balance the nitrogen-carbon ratio of their bodies. This will decrease the aphids' population and the honeydew production as well. As a result, the food sources of ants at low-altitude sites would have more nitrogen-based than plant-based food 
(honeydew). Unfortunately, we did not consider the aphideating phenomenon in this work, but believe it deserves further investigation.

The results of our ${ }^{15} \mathrm{~N}$-labeled experiments at different altitudes varied, which suggests that ant-aphid mutualism might be context dependent and affect nutrient transfer in the food web. Thus, our proposed context dependency of ant-aphid mutualism may be an important factor that influences altitudinal variations in nutrient transfer. In this study, we did not address the functions in nutrient transfer of roots and animals in the soil. The transfer process in the belowground system is complex, and future studies must pay careful attention to the specific transfer process and consider the effects of abiotic factors on nutrient transfer.

Acknowledgements We thank Guorui $\mathrm{Xu}$ and Yanqin Chu, who have contributed substantially to the completion of the field investigation. We thank the anonymous reviewer for helpful comments on the manuscript. This research is supported by the National Natural Science Foundation of China (31370451, 31300368, and 31470481) and the State Key Laboratory of Urban and Regional Ecology Grant (SKLURE2013-1-02).

\section{References}

Buckley RC (1987) Interactions involving plants, homoptera, and ants. Annu Rev Ecol Evol Syst 18:111-135

Cardoso P, Silva I, De Oliveira NG, Serrano ARM (2007) Seasonality of spiders (Araneae) in Mediterranean ecosystems and its implications in the optimum sampling period. Ecol Entomol 32:516526. doi:10.1111/j.1365-2311.2007.00894.x

Davidson DW, Cook SC, Snelling RR, Chua TH (2003) Explaining the abundance of ants in lowland tropical rainforest canopies. Science 300:969-972. doi:10.1126/science.1082074

Defossez E, Selosse MA, Dubois MP, Mondolot L, Faccio A, Djieto-Lordon C, Mckey D, Blatrix R (2009) Ant-plants and fungi: a new three-way symbiosis. New Phytol 182:942-949. doi:10.1111/j.1469-8137.2009.02793.x

Fischer RC, Richter A, Wanek W, Mayer V (2002) Plants feed ants: food bodies of myrmecophytic Piper and their significance for the interaction with Pheidole bicornis ants. Oecologia 133:186192. doi:10.1007/s00442-002-1000-y

Gibb H, Cunningham SA (2011) Habitat contrasts reveal a shift in the trophic position of ant assemblages. J Anim Ecol 80:119-127. doi:10.1111/j.1365-2656.2010.01747.x

Heil M, McKey D (2003) Protective ant-plant interactions as model systems in ecological and evolutionary research. Annu Rev Ecol Evol Syst 34:425-453. doi:10.1146/annurev. ecolsys.34.011802.132410

Holldobler B, Wilson EO (1990) The ants. Harvard University Press, Cambridge, pp 897-898

Johansson T, Gibb H (2012) Forestry alters foraging efficiency and crop contents of aphid-tending red wood ants, Formica aquilonia. PLoS ONE 7:e32817. doi:10.1371/journal.pone.0032817

Jurgensen MF, Finer L, Domisch T, Kilpelainen J, Punttila P, Ohashi M, Niemela P, Sundstrom L, Neuvonen S, Risch AC (2008) Organic mound-building ants: their impact on soil properties in temperate and boreal forests. J Appl Entomol 132:266-275. doi:10.1111/j.1439-0418.2008.01280.x
Kalnihs M, Dreimanis J (2007) Protected insects of Latvia-Lasius fuliginosus (Latreille, 1798) (Hymenoptera: Formicidae). Latv Entomol 44:95-102

Liu XZ, Wang GA, Li JZ, Wang Q (2009). Nitrogen isotope composition characteristics of modern plants and their variations along an altitudinal gradient in Dongling Mountain in Beijing. Sci China Ser D, 39:1347-1359. doi:10.1007/ s11430-009-0175-z

Martinelli LA, Piccolo MC, Townsend AR, Vitousek PM, Cuevas E, Mcdowell W, Robertson GP, Santos OC, Treseder K (1999) Nitrogen stable isotopic composition of leaves and soil: tropical versus temperate forests. Biogeochemistry 46:45-65. doi:10.1007/BF01007573

Palmer TM, Stanton ML, Young TP, Goheen JR, Pringle RM, Karban $\mathrm{R}$ (2008) Breakdown of an ant-plant mutualism follows the loss of large herbivores from an African Savanna. Science 319:192195. doi:10.1126/science. 1151579

Petry WK, Perry KI, Mooney KA (2012) Influence of macronutrient imbalance on native ant foragingand interspecific interactions in the field. Ecol Entomol 37:175-183. doi:10.1111/j.1365-2311.2012.01349.x

Ponsard S, Arditi R (2000) What can stable isotopes $\left(\delta^{15} \mathrm{~N}\right.$ and $\left.\delta^{13} \mathrm{C}\right)$ tell about the food web of soil macro-invertebrates? Ecology 81:852-864. doi:10.1890/0012-9658(2000.081) [0852:WCSINA]2.0.CO;2

Post DM (2002) Using stable isotopes to estimate trophic position: models, methods, and assumptions. Ecology 83:703-718. doi:10.1890/0012-9658(2002)083[0703:USITET]2.0.CO;2

Rico Gray V (1993) Use of plant-derived food resources by ants in the dry tropical lowlands of coastal Veracruz, Mexico. Biotropica 25:301-315. doi: $10.2307 / 2388788$

Rosumek FB, Silveira FAO, Neves FD, Barbosa NPD, Diniz L, Oki Y, Pezzini F, Fernandes GW, Cornelissen T (2009) Ants on plants: a meta-analysis of the role of ants as plant biotic defenses. Oecologia 160:537-549. doi:10.1007/s00442-009-1309-x

Sipura M (2002) Contrasting effects of ants on the herbivory and growth of two willow species. Ecology 83:2680-2690. doi:10.1890/0012-9658(2002)083[2680:CEOAOT]2.0.CO;2

Solano PJ, Dejean A (2004) Ant-fed plants: comparison between three geophytic myrmecophytes. Biol J Linn Soc 83:433-439. doi:10.1111/j.1095-8312.2004.00381.x

Stadler B, Dixon AFG (2005) Ecology and evolution of aphid-ant interactions. Annu Rev Ecol Evol Syst 36:345-372. doi:10.1146/ annurev.ecolsys.36.091704.175531

Tillberg CV, Mccarthy DP, Dolezal AG, Suarez AV (2006) Measuring the trophic ecology of ants using stable isotopes. Insect Soc 53:65-69. doi:10.1007/s00040-005-0836-7

Trager MD, Bhotika S, Hostetler JA, Andrade GV, Rodriguez-Cabal MA, McKeon CS, Osenberg CW, Bolker BM (2010) Benefits for plants in ant-plant protective mutualisms: a meta-analysis. PLoS ONE 5:e14308. doi:10.1371/journal.pone.0014308

Treseder KK, Davidson DW, Ehleringer JR (1995) Absorption of ant-provided carbon dioxide and nitrogen by a tropical epiphyte. Nature 375:137-139. doi:10.1038/375137a0

Wagner D, Nicklen EF (2010) Ant nest location, soil nutrients and nutrient uptake by ant-associated plants: does extrafloral nectar attract ant nests and thereby enhance plant nutrition? J Ecol 98:614-624. doi:10.1111/j.1365-2745.2010.01640.x

Wardle DA, Hyodo F, Bardgett RD, Yeates GW, Nilsson MC (2011) Long-term aboveground and belowground consequences of red wood ant exclusion in boreal forest. Ecology 92:645-656. doi:10.1890/10-1223.1

Wilder SM, Holway DA, Suarez AV, LeBrun EG, Eubanks MD (2011) Intercontinental differences in resource use reveal the importance of mutualisms in fire ant invasions. Proc Natl Acad Sci USA 108:20639-20644. doi:10.1073/pnas.1115263108 
Wimp GM, Whitham TG (2001) Biodiversity consequences of predation and host plant hybridization on an aphid-ant mutualism. Ecology 82:440-452. doi:10.1890/0012-9658(2001)082[0440:BCOP $\mathrm{AH}] 2.0 . \mathrm{CO} ; 2$

Yao I, Akimoto S (2001) Ant attendance changes the sugar composition of the honeydew of the drepanosiphid aphid Tuberculatus quercicola. Oecologia 128:36-43. doi:10.1007/s004420100633

Yi XF, Zhang XA (2005) Application of stable isotopic approach in ecology. Chin J Ecol 24:306-314. doi:10.1329 2/j.1000-4890.2005.0258

Yu PJ, Xu HL, Wang W, Zhang P, Zhao XF, Liu XH, Zhang QQ (2012) Response of ${ }^{15} \mathrm{~N}$ isotope in plant to water change in desert grassland. Arid Zone Res 29:347-351. doi:10.13866/j. azr.2012.02.009

Zhang YX, Ma KM, Anand M, Fu BJ (2006) Do generalized scaling laws exist for species abundance distribution in mountains? Oikos 115:81-88. doi:10.1111/j.2006.0030-1299.15021.x
Zhang S, Zhang YX, Ma KM (2012) Different-sized oak trees are equally protected by the aphid-tending ants. Arthropod Plant Interact 6:307-314. doi:10.1007/s11829-011-9172-1

Zhang S, Zhang YX, Ma KM (2015) Mutualism with aphids affects the trophic position, abundance of ants and herbivory along an elevational gradient. Ecosphere 6:1-11. doi:10.1890/ ES15-00229.1

Zhong M (2013) The characteristics of carbon and nitrogen stable isotope ratio research. Dissertation, Dalian Maritime University

Zhou YC, Cheng XL, Fan JW (2012) Research progress of relationships between plant $\delta^{15} \mathrm{~N}$ and influence factors. Acta Agrestia Sin 20:981-989 